\title{
Modelling the Spatial Distribution of Arsenic in Water and Its Correlation with Public Health, Central Indus Basin, Pakistan
}

\author{
Yawar Hussain', Adil Dilawar², Sadia Fida Ullah³, Gulraiz Akhter4, \\ Hernan Martinez-Carvajal1,5, Muhammad Babar Hussain'6, \\ Abdul Qayyum Aslam7 \\ ${ }^{1}$ Department of Civil and Environmental Engineering, University of Brasilia, Brasilia, Brazil \\ ${ }^{2}$ Department of Physics, University of Sargodha, Sargodha, Pakistan \\ ${ }^{3}$ Department of Biological Sciences, University of Brasilia, Brasilia, Brazil \\ ${ }^{4}$ Department of Earth Sciences, Quaid-i-Azam University, Islamabad, Pakistan \\ ${ }^{5}$ Faculty of Mines, National University of Colombia at Medellín, Medellín, Colombia \\ ${ }^{6}$ Department of Theoretical and Astrophysics, Xiamen University, Xiamen, China \\ ${ }^{7}$ College of Earth and Environmental Sciences, University of the Punjab, Lahore, Pakistan \\ Email: yawar.pgn@gmail.com
}

Received 9 January 2016; accepted 30 January 2016; published 4 February 2016

Copyright (C) 2016 by authors and Scientific Research Publishing Inc.

This work is licensed under the Creative Commons Attribution International License (CC BY). http://creativecommons.org/licenses/by/4.0/

(c) (i) Open Access

\section{Abstract}

Like India, Bangladesh and China, Pakistan also has some regions where concentration of Arsenic in water has crossed the WHO safe drinking water limits, $10 \mathrm{ppb}$. Presence of Arsenic in drinking water is causing serious human health issues for the local residents of Sindh and southern Punjab, which needs serious attention. The present study is focused on the spatial distribution of Arsenic in groundwater and its relationship with the major reported human diseases at settlement level of District Layyah. Data collection is done by taking water samples from hand pumps and health issues reported at the local health care centers adjoining to that sampling pump. The spatial distribution of Arsenic concentration in groundwater is done by using Inverse Distance Weighting (IDW) technique. Arsenic Risk Index (ARI) is developed based of WHO health standards, and then used to divide study area into two Arsenic Risk Zones as no risk and high risk with As values less or equal to $10 \mathrm{ng} \cdot \mathrm{ml}^{-1}$ and greater than $10 \mathrm{ng} \cdot \mathrm{ml}^{-1}$, respectively . In the final step these zones were correlated with the diseases at village level. The results show that, Arsenic is high near the Indus River and it decreases in central and eastern parts towards Chenab River. Same trend of Indo-Chenab Arsenic gradient is followed by skin diseases among the people especially, in tehsil Layyah and tehsil Koror. It is concluded that high Arsenic amount in water and skin diseases are highly dependent on the recharge from Indus River. 


\section{Keywords}

\section{Arsenic, GIS, Human Health, IDW, Indus Basin, Layyah}

\section{Introduction}

Pakistan like other major Asian countries (Banghladesh, India and China), is suffering from the problem of Arsenic (As) in its drinking water [1]. The contaminated water with Arsenic is a serious public health concern especially in Sindh [2] and southern parts of Punjab province [3]. This sort of contamination in Punjab is on rise both in space [4] and time [5]. Arsenic is the 12th most abundant component of earth; its major sources are geology and anthropogenic pollutions. Arsenic is an organic component of earth crust; it is present in earth atmosphere like air, water and soil [6]. But, if this concentration in earth's environment exceeds up to certain limits, it can cause serious human health issues. Some common diseases caused by the intake of Arsenic in human body are, cancers of the bladder, lung and skin, reproductive and developmental effects, cardiovascular diseases, and skin effects on palms and soles [4]. Its reactions with other elements result in organic and inorganic compounds. Organic compounds which are taken along with fruits and vegetables are also very harmful and are formed by reaction of carbon dioxide with Arsenic. Inorganic Arsenic is more harmful than organic one [6]. In this analysis only one effect of Arsenic contaminated water on population of district Layyah has been taken under consideration i.e. skin problem on palms and soles (SPPS). Geographic Information System (GIS) has proved an effective tool for the large data handling and spatial modelling application in hydrology. The use of GIS for water studies has increased greatly because of its attractive data handling capabilities, geo-referencing and geo-statistical applications. Present spatial modelling of Arsenic is performed in GIS which offers an excellent environment for such an analysis.

In 1996 As in Pakistan was found [7]. Pioneer work on problem of As in Pakistan was done by Pakistan Council of Research in Water Resources (PCRWR) in collaboration with many national, international, governmental and non-governmental organizations. In the water quality monitoring of Pakistan, two important initiatives which were taken by PCRWR along with national and international organizations are National Water Quality Monitoring Programme (NWQMP) and Arsenic Monitoring and Mitigation Programme (AMMP). The results of AMMP have revealed that As exists in southern Punjab and Sindh. About 38.28\% of the samples collected from Southern Punjab contain As concentration above the safe drinking limit of WHO. In Sindh province $11.6 \%$ of the total samples have As beyond safe limits. After that lots of effectors were made by different NGOs and government agencies in order to mitigate impacts of As on public health. Reference [8] carried As and other groundwater parameters monitoring study in district Muzaffargarh which lies at northern side of study area. In this study 49 samples were taken at various depths and at various locations both within and outside the city. The objective of this study was to see the impact of urbanization on As amount in groundwater. These samples were tested for WHO standards. All of those wells deeper than $30 \mathrm{~m}$ located in urban area have As $>10 \mathrm{ng} \cdot \mathrm{ml}^{-1}$. Authors concluded that source of As is untreated urban wastes and it increases with depth. A water quality assessment of Dera Ghazi Khan (lies at western side of district Layyah) was done by [9]. In this study 32 samples were collected through the city and physiochemical analysis was performed. The focus of study was to target Arsenic in drinking water of this rapidly growing city. The results of this analysis have shown that all samples lie in permitable As range, while other physiochemical parameters have crossed the WHO standard values. Another study was conducted in three rural areas of Punjab (Chichawatni, Vehari, Rahim Yar Khan) where As along with other chemicals was determined from water samples, then a water quality index was developed for these regions [10]. Reference [11] did an excellent study in district Layyah by taking 198 water samples at different locations within the Layyah. The results are $88 \%$ samples in range of $0-10 \mathrm{ppb}$. Authors found that As concentration is in the range of $4-62 \mathrm{ng} \cdot \mathrm{ml}^{-1}$ and overall average value is $10 \mathrm{ng} \cdot \mathrm{ml}^{-1}$. The effects of depths on As were checked; they concluded the same results as [8] in Muzafargarh that As has no link with change in depth. In this study another import conclusion was made that As has no spatial uniformity for the district Layyah. Reference [12] conducted an interesting study in which authors make a casualty link between skin diseases among the peoples and role of Indus River in contaminating aquifer with As which was then used for drink and agricultural activities in flood plain of Indus River. In another import study, a link between As rich water and vegetables cultivated with this water was made in Sindh province. From this study it is concluded that As from 
irrigated water can transfer to crops grown with this water [13].

In this study an attempt has been made to mark the different Arsenic risk zones according to World Health Organization (WHO) criteria as $10 \mathrm{ppb}$. In the second step a link between Arsenic concentration and its impact on human health is made. Two assumptions are tested: 1) concentration of As is related positively to the recharge from river; 2) high concentration of As in water is related positively to the reported skin problems on palms and soles among the people.

\section{Material and Methods}

District Layyah lies in central Indus basin having geographic co-ordinates latitude $30^{\circ} 34^{\prime} 48^{\prime \prime}-31^{\circ} 22^{\prime} 48^{\prime \prime}$ north and longitude $70^{\circ} 43^{\prime} 58.8^{\prime \prime}-71^{\circ} 50^{\prime} 60^{\prime \prime}$ east. There are two hydrological boundaries of the region marked by the mighty Indus River and its tributary Chenab River (Figure 1). The Indus River flows at the northern side which greatly effects the study area, both in terms of risks and benefits. It has played an important role in the geology and agriculture of the area. Major recharge of groundwater is from Indus River. The river Chenab marked the western side of the area but it has very little role in hydrology of area. District Bhakhar at north and Muzafargarh at south are the two administrative boundaries of the study area. Climate of Layyah is extreme. Climatically, the region is divided into two seasons as winter and summer. It has two crop seasons as Rabi and Kharif. Major crops are cotton and sugarcane. Main landuse is agricultural land, there are very few industries. Another basic characteristic of the Layyah's climate is the extreme aridity. Usually, evapotranspiration is higher than rainfall. There is no metrological station inside the study area so rainfall data of Multan station is plotted in Figure 2.

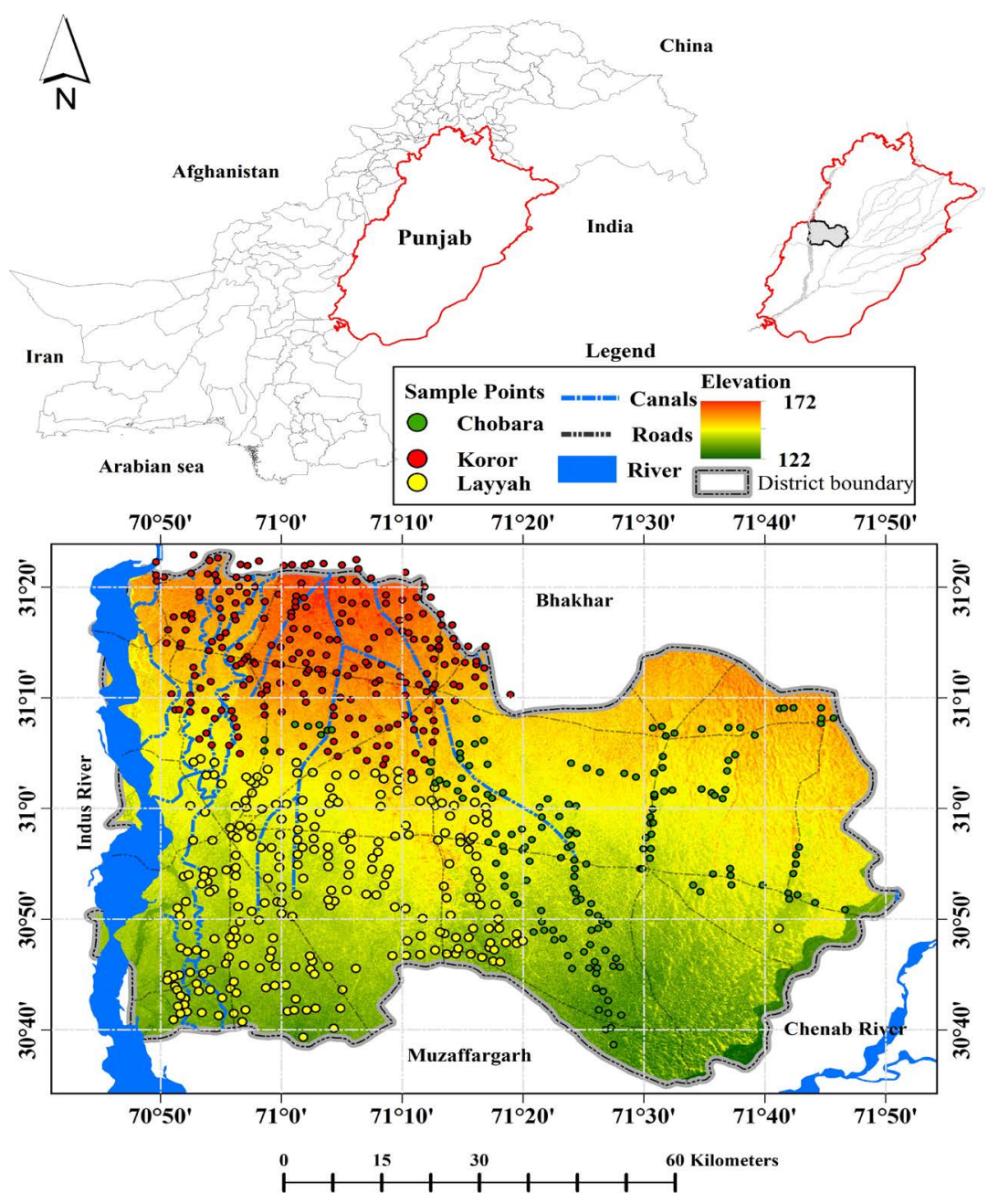

Figure 1. Regional location of study area on Pakistan map with major canals, rivers, roads and sampling points. 


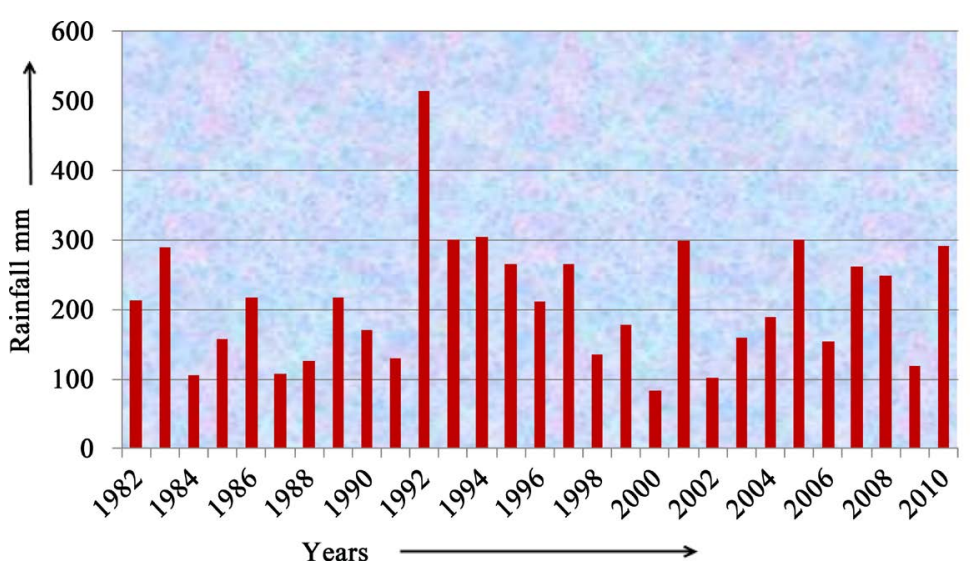

Figure 2. Average annual rainfall from year 1982-2010 of Multan station.

District Layyah has three smaller administrative units as Chobara, Layyah, and Koror. Total area of district Layyah is about $6692 \mathrm{~km}^{2}$. The direction of groundwater flow is in south-west direction [14]. Maximum elevation is 172 meter and minimum elevation 124 meters (Figure 1).

Geology of the region is alluvium which consists of alluvial and Aeolian deposits of quaternary age over basement rocks, thickness of which is still unknown [15]. It contains a mixed and very complex lithology. Basic lithological units are sand, slit and clays. Clays and silt occur in the form of small lens which are not possible to map at the scale of available data [16]. Thus, geology is usually related to physiography of the area. There are two physiographic units as alluvial, the deposition is done by rivers, and other basic unit is Aeolian or wind deposit. Wind storms are common climatic features of the region. Active flood plain, abandon flood plan and sand dunes are the common physiographic units of study area. Sand dunes are small elevated features of about 3 meters average height and are continuously being deposited and redeposited by the actions of air currents (storms). Topography of the area is flat but it has very well developed canal system which is a basic source of surface and groundwater for Layyah's population and its agriculture.

The data collection is done by PCRWR. The data sampling was done at settlement level. Groundwater samples were taken from local wells at depth of water table and then were analyzed for their Arsenic concentrations in the laboratory of PCRWR. In this laboratory work water samples were tested for As concentration along with many other physiochemical parameters which are related to water quality assessment (http://www.pcrwr.gov.pk). The latitude, longitude of each sampling well is determined by using Global Positioning System (GPS). The data taken from PCRWR consists of latitude, longitude, elevation, depth of water table, and concentration of Arsenic in each water sample. The medical data of reported skin problem on palms and soles of the people is taken from local medical centers near sampling point.

Data from excel sheet is imported in ArcGIS 10.1 and assigned X, Y values from the sheet. In this way a point shape file is created for all the sampling points. Then the all these points were projected to UTM (Universal Transverse Mercator) at 42 North Zone with WGS 1984 datum using projection and transformation tool of ArcGIS 10.1 software. Then these values are interpolated using IDW (Inverse Distance Weight) technique. IDW worked on the principle that value at unmeasured point can be predicted from neighboring measured points by assigning a weight factor, which varies inversely with the distance from measured point [17]. The formula of application IDW is similar like other interpolation techniques, the difference lies in computing weight [18].

$$
Z=[W(1) \times Z(1)+\cdots+W(n) \times Z(n)] /[W(1)+\cdots+W(n)]
$$

where, $Z$ is value at point $P$ (say), $W$ is wait, it is calculated by following relation for IDW interpolation.

$$
W(i)=\frac{1}{\text { Distance }}\left(P, P(i)^{p}\right)
$$

where, exponent " $p$ " is the distance between measuring point and data point [19].

Spatial extension tool of ArcGIS 10.1 software is used to interpolate these data points. The result of this interpolation is divided into two zones based on WHO limits, as no risk which has Arsenic concentration value 
less or equal to $10 \mathrm{ppb}$ and the zone which has values greater than $10 \mathrm{ppb}$ is taken as high risk zone. This zonation of As concentration is done by using quartile classification tool of ArcGIS. In this classification value is assigned to each point and it is suitable for linear data all the data point is one zone are assigned a single value which can also cause some errors in final measurement [20]. A color scheme is used to resent these two zones in which red color is used to represent high risk zone and a brownish shade is used to indicate no risk zone (Figure 3). Query builder is used for the classification of sample points which lie in three different tehsils. Statistical summary of all the samples falling in three tehsils are calculated (Table 1). On the final Arsenic concentration map the public health data is plotted and is checked for the type of reported diseases present at each zone.

\section{Results and Discussion}

For the ease of data processing study area is divided into three smaller administrative units, as Layyah, Koror and Chobara. Total 640 water samples are analysed for the entire study area. Tehsil Layyah contains 250 samples out which 200 samples lie below the WHO standards. The minimum value Arsenic is 0 and maximum value is 150 with mean value 8.4 and standard deviation is 18.7. Statistical summary of tehsil Chobara is $0,25,1.4$ and 3.7 as minimum, maximum, mean value and standard deviation, respectively. Total number of samples is 155 . Tehsil Koror has 235 sampling points. Arsenic values vary from minimum 0 to maximum 100 (Table 1). Frequency distribution along with statistical summary is given in Figure 4, which shows that most of samples lie in low value range. Frequency distributions of the samples of tehsil Koror is more disperse than the other two tehsils. The results of spatial modelling (Figure 3) show that concentration of Arsenic related positively to the recharge from Indus River and its canals system, which deviates its water to comparatively far lands. Near Indus River Arsenic concentration is higher than the accepted limits of WHO, which is associated with higher health risk. The quality of almost all the villages at the bank of Indus River is very bad which need special attention from local and regional agencies which are concerned with public health (Table 1). The region in active flood plain of Indus River lies in high risk zone and also has high skin problem cases. While in central and eastern

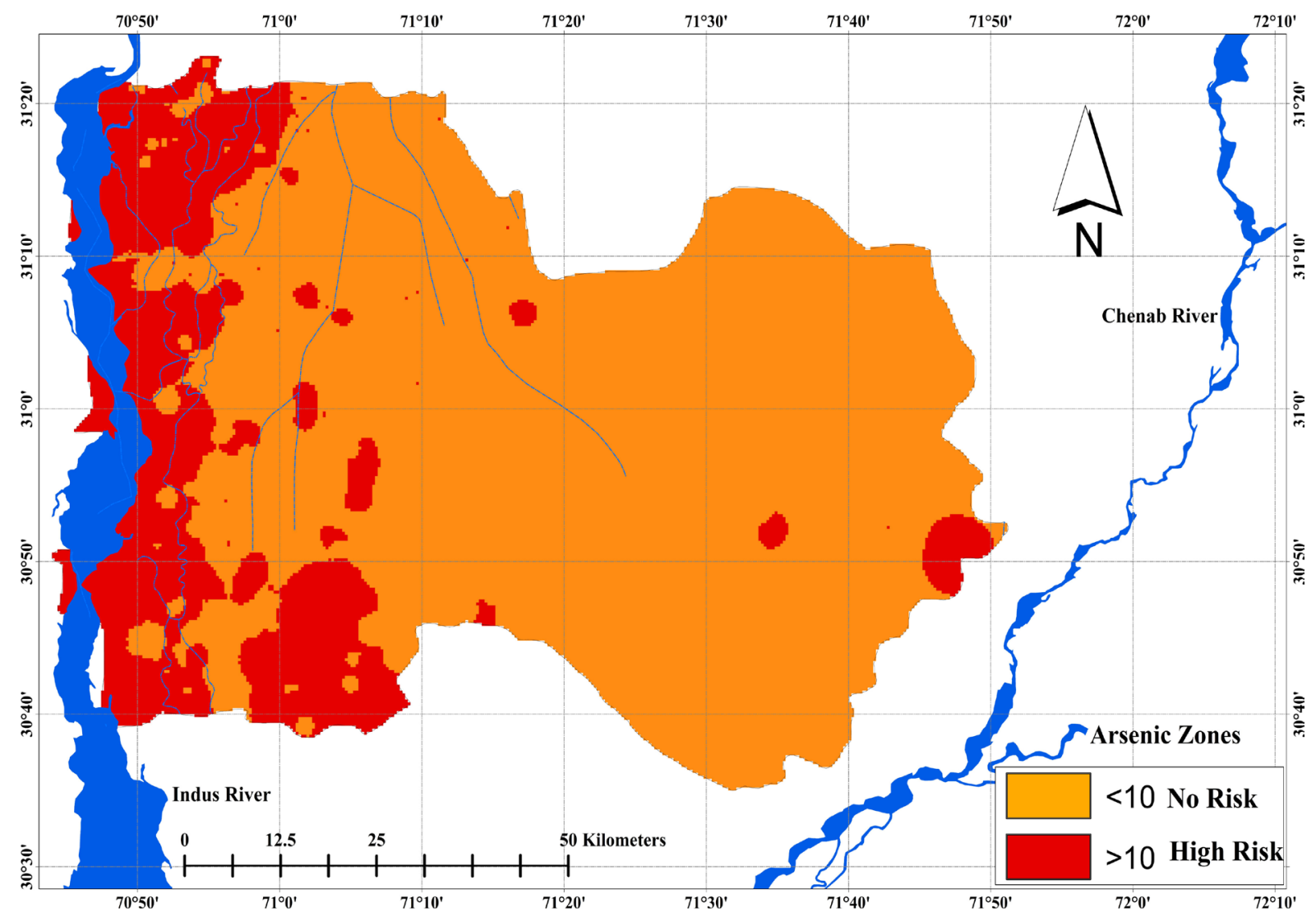

Figure 3. Spatial distribution of as in groundwater and Arsenic risk zones of district Layyah. 

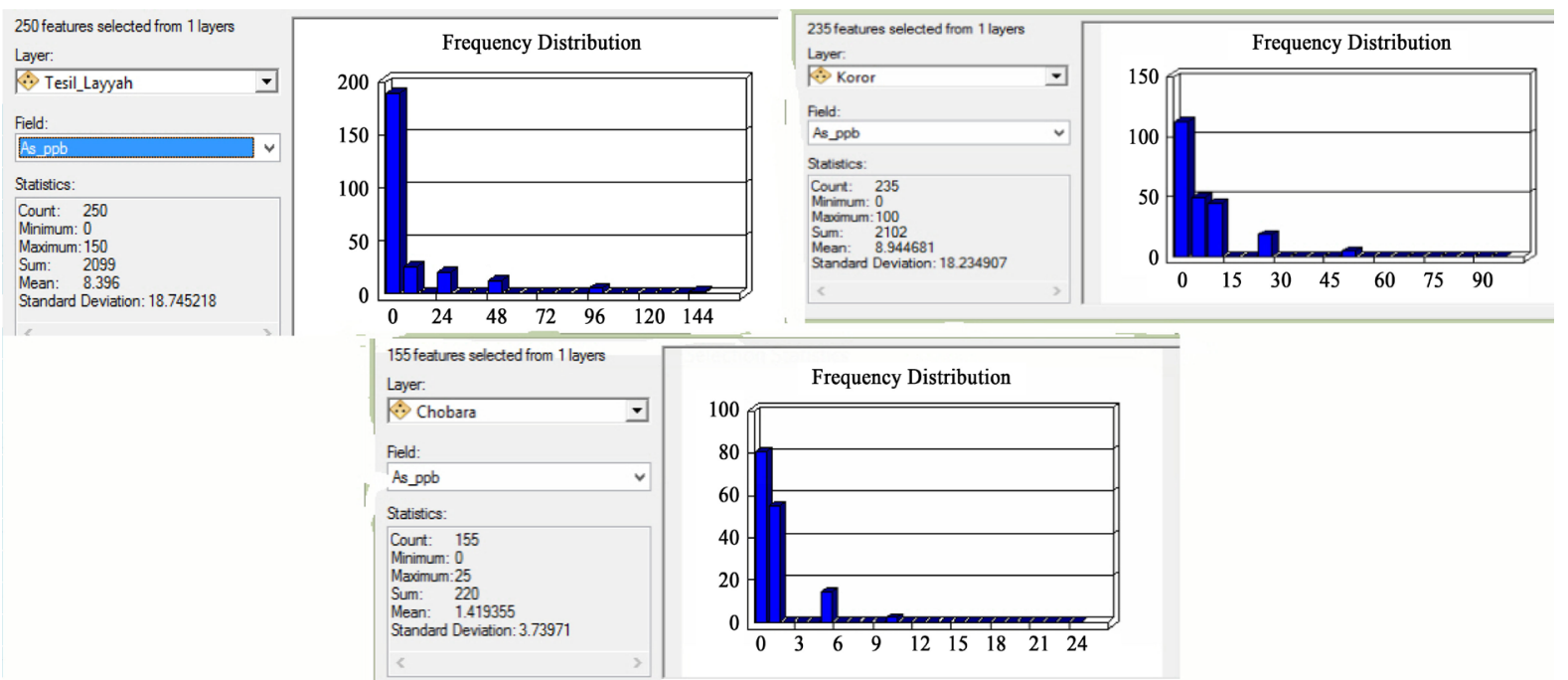

Figure 4. Frequency distribution along with statistical summary of as in water of three tehsils, starting from right Layyah, Koror and Chobara.

parts towards Chenab River, most of water samples have Arsenic content less than $10 \mathrm{ng} \cdot \mathrm{ml}^{-1}$. From Figure 3 it can be seen clearly, that there is decreasing values of Arsenic concentration in the groundwater because of low recharge. This Indo-Chenab Arsenic decreasing gradient is a clear indication of the role of River Indus in contaminating the underlying aquifer. This decreasing value of recharge and Arsenic in the samples from Indus River to Chenab River is suited well with the numbers of reported skin diseases at local medical centers.

Toor and Tahir (2008) [11] concluded from their study in seven districts of Pakistan including Layyah, that there is no spatial uniformity between amount of Arsenic content in water and they also showed that there is no correlation with sampling depth either. But in this study an interesting conclusion is made that amount of Arsenic in water shows certain level of uniformity with the proximity to Indus River and its cherished Indus Basin Canal System.

In final step trends of reported skin diseases are analyzed. It can been seen in Table 1, that intensity of reported diseases correlate well with the concentration of As in water sample of that area, but in some parts especially in tehsil Chobara where there it relate to measure As concentration negatively. Tehsil Chobara lies in no risk zone but it has highest number of skin disease cases about 39\% of the total surveyed locations. Only three samples out of 155 have As concentration greater than $10 \mathrm{ppb}$ (Table 1). One possible reason of this negativity in correlation is the dependency of Chobara population on the agricultural products like fruits and vegetables which are irrigated with contaminated water in the high risk zone. Dependency on the Arsenic rich irrigated agricultural products can be considered as a secondary cause of skin problems [13]. So there are two possible causes of skin problems, direct and indirect contact with As contaminated water. Results of this analysis show that two tehsils Layyah and Koror has skin problems among their residents, because of direct as well as indirect contact with As, through food items and by drinking As rich water, while tehsil Chobara's people get As throung food items cultivated near Indus River. Tehsil Chobara which is far from Indus River and satisfy our first assumption that amount of As in groundwater is directly related to recharge from Indus, while it violate second assumption that high As in groundwater leads apparently high skin problems. Some common expression of As in the form skin problems on palms and soles are mention in Figure 5. Settlement wise comparisons of different survey locations are tabulate in Table 2, which shows that Ada Amir Choke, Basti Soonhara and Basti Ahmad Khan are at high risk and need serious attentions.

\section{Conclusion}

This study was carried to achieve dual objectives: 1) the distribution of As through spatial modelling and respective Arsenic risk zoning using GIS environment; 2) determination of correlation between Arsenic risk zones and skin diseases of the local people near sampling point. The resultant risk zones show that As is maximum near Indus River and canals while it is low in low recharge areas. It means that As brings to Layyah by River 
Table 1. Tehsil wise comparison of Arsenic concentration and skin problem.

\begin{tabular}{|c|c|c|c|c|c|c|c|}
\hline No & Tehsils & No. of sample & $\begin{array}{c}\text { As concentration } \\
\left(\mathrm{ng} \cdot \mathrm{ml}^{-1}\right)\end{array}$ & $\begin{array}{c}\leq 10 \\
\text { (\% samples) }\end{array}$ & $\begin{array}{c}>10 \\
\text { (\% samples) }\end{array}$ & $\begin{array}{c}\text { Average value } \\
\left(\mathrm{ng} \cdot \mathrm{ml}^{-1}\right)\end{array}$ & SPPS cases $(\%)$ \\
\hline 1 & Layyah & 250 & $0-150$ & 86 & 14 & 8.37 & 50 \\
\hline 2 & Koror & 235 & $0-100$ & 87.7 & 12.3 & 8.94 & 25 \\
\hline 3 & Chobara & 155 & $0-25$ & 98 & 2 & 1.67 & 39 \\
\hline
\end{tabular}

Table 2. Settlement wise comparison of Arsenic concentration and skin problems.

\begin{tabular}{|c|c|c|c|c|c|c|c|}
\hline No. & Sample code & $\mathbf{X}$ & $\mathbf{Y}$ & Name of Settlement & Risk & As (ppb) & SPPS \\
\hline 1 & LAY-262 & 71.267778 & 31.029167 & Chak No.363/TDA & No & 1 & Nil \\
\hline 2 & LAY-316 & 71.625833 & 31.080556 & Dera Zulfiqar Ali Kot Hassu Wala & No & 10 & Yes \\
\hline 3 & LAY-453 & 71.011667 & 31.253889 & Ada Amir Chok UC Gerey Wala & High & 25 & Yes \\
\hline 4 & LAY-542 & 70.841667 & 31.248889 & Muhammad Wala Khoo UC & High & 10 & Yes \\
\hline 5 & LAY-605 & 70.953611 & 31.365556 & Basti Soonhara & High & 25 & Nil \\
\hline 6 & LAY-662 & 71.2375 & 31.186667 & Chak No.243 Azafi Basti & Low & 1 & Nil \\
\hline 7 & LAY-27 & 71.029167 & 31.012222 & Chak-No.135/TDA & High & 25 & Yes \\
\hline 8 & LAY-130 & 70.868611 & 30.859722 & Basti Jakhar & High & 25 & Yes \\
\hline 9 & LAY-193 & 71.218889 & 30.813611 & Chak-No.455 & No & 0 & Nil \\
\hline 10 & LAY-225 & 70.851389 & 30.681944 & Basti Ahmad Khan & High & 50 & Yes \\
\hline
\end{tabular}
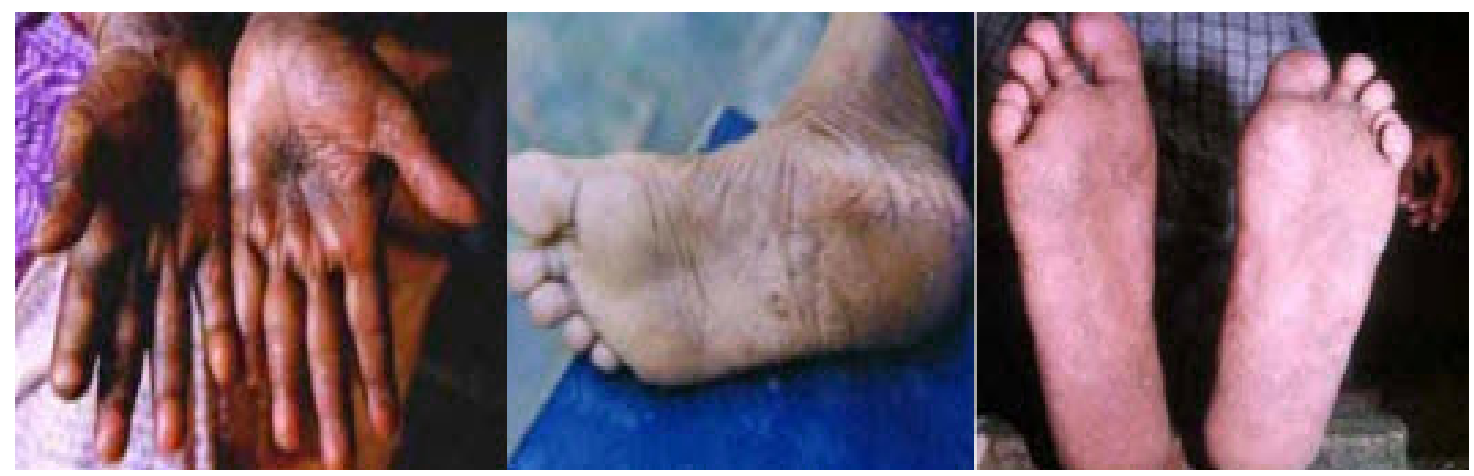

Figure 5. Example of skin problems on the palms of hands and feet Punajab, Pakistan.

Indus. There are large numbers of reported cases in high recharge and high As concentrations in tehsil Layyah and Koror. It is concluded from this study that people get skin diseases by two possible ways: directly connecting with As rich water (Layyah and Koror) and relying on agricultural products grown in regions of high As groundwater or aquifer (Chobara). The results of study [1] in small village of Raheem Yar Khan which lies at the bank of Indus River, are quite validatory to our assumption that Indus River has gifted the aquifer of district Layyah with Arsenic. One possible cause of the high Arsenic in water may be because of buried nuclear waste. To get certification about this possible cause of As, a detailed study is required.

\section{Acknowledgements}

Author would like to acknowledge PCRWR and Dr. A.D. Khan for helping this research. We would also like to thank Ms. Farzana Ahmad Deen for critically analyzing the article for possible English corrections.

\section{References}

[1] Haq, I.U. and Baig, M.A., Nabi, D. and Wajid Hayat, W. (2007) Groundwater Arsenic Contamination-AMulti Directional Emerging Threat to Water Scarce Areas of Pakistan. 6th International IAHS Groundwater Quality Conference, Fremantle, Western Australia, 2-7 December 2007, 24. 
[2] Ahmad, T., Kahlown, M.A., Tahir, A. and Rashid, H. (2004) Arsenic an Emerging Issue: Experience from Pakistan. People Centered Approaches to Water and Environmental Sanitation. Thirtieth WEDC International Conference, WEDC, Vientiane, 25-29 October 2004, 459-466. http://dx.doi.org/10.1007/978-81-322-2298-9_2

[3] Farooqi, A. (2015) Status of As and $\mathrm{F}^{-}$Groundwater and Soil Pollution in Pakistan. Arsenic and Fluoride Contamination, 21-33. http://dx.doi.org/10.4236/jwarp.2013.512132

[4] Ali, S.S., Karim, N., Munshi, A.B., Siddqui, I. and Khan, F.A. (2013) Health Hazards among Coastal Villagers of Pakistan Due to Arsenic Contaminated Drinking Water. Journal of Water Resource and Protection, 5, 1235-1241.

[5] Khan, M.N. (2012) Application of Geophysical Method to Explore the Aquifer and Evaluate Its Parameter; Demarcation of Low Salinity Groundwater of Layyah Area. MPhil Dissertation, Quaid-i-Azam University, Islamabad.

[6] Sana, S., Javed, Z., Chand, S., Hashmi, N. and Ahmad, M. (2015) Spatial Distribution of Arsenic Concentration in Drinking Water Using Kriging Techniques. Science International, 27, 949-954.

[7] Haque, I.U. and Nasir, M. (2015) Monitoring and Impact Evaluation System for Arsenic Mitigation InterventionsArsenic Contamination Areas of Pakistan. International Journal of Environmental Monitoring and Analysis, 3, 67-78.

[8] Nickson, R.T., McArthur, J.M., Shrestha, B., Kyaw-Myint, T.O. and Lowry, D. (2005) Arsenic and Other Drinking Water Quality Issues, Muzaffargarh District, Pakistan. Journal of Applied Geochemistry, 20, 55-68. http://dx.doi.org/10.1016/j.apgeochem.2004.06.004

[9] Malana, M.A. and Khosa, A. (2011) Groundwater Pollution with Special Focus on Arsenic, Dera Ghazi Khan-Pakistan. Journal of Saudi Chemical Society, 15, 39-47. http://dx.doi.org/10.1016/j.jscs.2010.09.009

[10] Shakoor, M., et al. (2015) Unraveling Health Risk and Speciation of Arsenic from Groundwater in Rural Areas of Punjab, Pakistan. International Journal of Environmental Research and Public Health, 12, 12371-12390. http://dx.doi.org/10.3390/ijerph121012371

[11] Toor, I.A. and Tahir, S.N.A. (2009) Study of Arsenic Concentration Levels in Pakistani Drinking Water. Polish Journal of Environmental Studies, 18, 907-912.

[12] Fatima, Z., et al. (2009) Health Burden of Skin Lesions at Low Arsenic Exposure through Groundwater in Pakistan. Is River the Source? Environmental Research, 109, 575-581. http://dx.doi.org/10.1016/j.envres.2009.04.002

[13] Abbas, M., Parveen, Z., Iqbal, M., Riazuddin, M., Iqbal, S., Ahmed, M. and Bhutto, R. (2010) Monitoring of Toxic Metals (Cadmium, Lead, Arsenic and Mercury) in Vegetables of Sindh, Pakistan. Kathmandu University Journal of Science, Engineering and Technology, 6, 60-65. http://dx.doi.org/10.3126/kuset.v6i2.4013

[14] Hanif, S. (2013) 3D Regional Groundwater Modeling of Thal Doab, Central Indus Basin, Punjab. Master’s Dissertation, Bahria University, Islamabad.

[15] Hussain, Y. (2014) Hydrogeophysical Investigations and GIS Vulnerability Mapping of Kot Addu. Master's Dissertation, Department of Earth Sciences, Quaid-i-Azam University, Islamabad.

[16] Greenman, D.W., Swarzenski, W.V. and Bennett, G.D. (1967) Groundwater Hydrology of the Punjab, West Pakistan with Emphasis on Problems Caused by Canal Irrigation. US Geological Survey Water-Supply Paper.

[17] Azpurua, M. and Ramos, K. (2010) A Comparison of Spatial Interpolation Methods for Estimation of Average Electromagnetic Field Magnitude. Progress in Electromagnetics Research, 14, 135-145. http://dx.doi.org/10.2528/PIERM10083103

[18] Childs, C. (2004) Interpolating Surfaces in ArcGIS Spatial Analyst. ArcUser, July-September, 32-35.

[19] Burrough, P.A. and McDonnell, R.A. (2011) Principles of Geographical Information Systems. Oxford University Press, Oxford.

[20] Data Classification Methods. http://pro.arcgis.com/en/pro-app/help/mapping/symbols-and-styles/data-classification-methods.htm 